\title{
Disparities in Youth Sports and Barriers to Participation
}

\author{
Nirav Kiritkumar Pandya ${ }^{1,2}$ \\ Accepted: 9 September 2021 / Published online: 8 October 2021 \\ (C) The Author(s) 2021
}

\begin{abstract}
Purpose of Review Youth sports participation has shifted from a school-based, seasonal activity to club-based, year-round activity over the past 10-15 years. Single sport specialization has become increasingly common with a concurrent increase in injury and burnout. Paralleling trends seen in other aspects of health care, disparities in regard to participation in youth sports, and subsequent injury treatment exist as well. Recognition of these disparities amongst coaches, parents, and athletes involved in youth sports are essential to promote the short- and long-term health of pediatric and adolescent athletes.

Recent Findings Multiple barriers exist for youth in regard to sports participation. Youth who come from families without extensive financial means are increasingly finding it difficult to play organized sports, with this trend holding when broken down by insurance status (public versus private). This problem is further exacerbated by the lack of community-based programming in locations where organized (albeit expensive) options do not exist. The lack of athletic trainers increases the divide, as well as the care that injured athletes receive (particularly in public schools within communities of color) is not equivalent to schools with extensive financial resources. Thus, ability to quickly return to play after injury and/or access the health care system is limited. This is further exemplified by inferior outcomes in regard to care for anterior cruciate ligament, meniscus, shoulder instability, and concussions in this population.

Summary Youth sports participation is laden with multiple disparities. This is unfortunately reflective of historical barriers to opportunities/advancements in multiple other areas of society. These disparities place certain groups of children at an uphill battle not only for participation when healthy, but also returning to participation when injured. Larger structural changes in youth sports are necessary to promote life-long, healthy physical activities for individuals most at risk.
\end{abstract}

Keywords Youth sports $\cdot$ Pediatric $\cdot$ Adolescent $\cdot$ Sports medicine $\cdot$ Disparity $\cdot$ Inequity

\section{Introduction}

A shift from school-based, sports participation to private, club sports has occurred within the USA. This is the background in which a "pay to play" model has developed excluding families who may not have the economic means to participate. This has been exacerbated by COVID-19 in which adolescent youth

This article is part of the Topical Collection on Gender and Racial Disparities

Nirav Kiritkumar Pandya

Nirav.Pandya@ucsf.edu

1 Department of Orthopedic Surgery, University of California San Francisco, San Francisco, CA, USA

2 Department of Pediatric Orthopedic Surgery, UCSF Benioff Children's Hospital Oakland, 747 52nd Street, Oakland, CA 94609, USA have been less physically active [1]. McGuine et al. examined 13,002 adolescent athletes during COVID-19 school closures and found a $74.1 \%$ prevalence of depressive symptoms in team sport participants [2•]. This is within a context of a pre-COVID environment in which only $7.9 \%$ of middle school and $2.1 \%$ of high schools provided daily structured physical education [3].

Preceding this change in activity patterns was a trend toward sports specialization. According to the Aspen Institute, children aged 6-12 years played an average of 2.11 sports in 2011, dropping to 1.87 in 2018 [4]. Single sport specialization is defined as intensive participation in a single sport at the exclusion of the sports [5]. This pattern of sporting participation has been associated with an increased risk of overuse syndromes of the knee, shoulder, and elbow [6••], as well as an increased risk of traumatic knee [7] and elbow injuries [8]. For many parents, the drive for athletic scholarship and/or preferred acceptance to college drives them even in the context of increased injury risk. 
Yet, only roughly $7 \%$ of high school athletes will play collegiately (of which only $2 \%$ will obtain a scholarship), and an even smaller percentage of these athletes will go on to play professionally [9-11]. Only 6 NCAA sports offer full scholarships (football, men's and women's basketball, women's gymnastics, volleyball, and tennis). What has been established is that athletes who play multiple sports are more likely to succeed professionally in sports such as the NBA [12], the NFL [13], and the MLB [14, 15]. In the drive for the rare scholarship, parents, coaches, and athletes not only are increasing their injury risk but also the disparities for sports participation as a byproduct.

\section{Financial Barriers to Play}

In an analysis of NCAA data, fewer than 1 of 7 students playing Division I sports were from families in which neither parent went to college [16]. This may be counterintuitive to those who believe scholarships are reflective of a desire to award those who may not have the economic means to pay for college. Yet, this is reflective of a trend in which significant financial barriers to play exist. Without the ability to participate, only those with robust financial means are able to place themselves in a position to attract the attention of collegiate coaches.

Underlying this is the tremendous financial incentive that the gate-keepers of youth sports, private clubs, have within a 15 billion dollar industry [17]. According to a TD Ameritrade survey, $63 \%$ of parents will pay $\$ 1200$ to $\$ 6000$ per year for sports participation, with nearly 1 in 5 paying more than $\$ 12,000$ a year [17]. Furthermore, according to the Aspen Institute, whereas $43 \%$ of children in homes earning more than $\$ 100,000$ were able to play sports, only $22 \%$ of children in homes with incomes less than $\$ 25,000$ participated [4••]. This had led to increased inactivity levels amongst those most at risk of developing long-term health conditions as adults. For families who cannot afford the average $\$ 693$ per sport per year to participate [4••], limited school-based options (particularly during COVID) has led to a lack of physical activity opportunities due to fees, transportation challenges, and equipment costs [18].

This discrepancy in participation based on income was shown in a recent study by Jayanthi et al. who found that as socio-economic status increased, youth athletes suffered more overuse injuries [19••]. This was postulated to be due to an increased incidence of sports specialization, more hours per week playing organized sports, higher ratio of weekly organized sports compared to free play, and preferential participation in individual sports [19••]. This was further demonstrated by Post et al. who demonstrated that families whose children played club sports spent a median of $\$ 1500$ dollars (range \$500-\$3000) per year, had household incomes greater than $\$ 100,000$, and had bachelor's degree or higher education [20••]. Barriers to participation for lower socio-economic groups are real within this specific demographic of youth.

With a de-emphasis on school-based sports, the only options available to families are expensive and cost-prohibitive. This decline in participation is particularly striking amongst communities of color [4••]. Hyde et al. found that youth sports participation was highest amongst white males and increased with education/household income [21•]. Even when looking at youth sports participation through the lens of health insurance, Fabricant et al. found that youth with government/ Medicaid or lacking health coverage had low levels of physical activity [22]. The barriers to participation are not only financial but also geographic. Communities in which there are higher levels of college attainment are more likely to offer options for club sports such as flag football [23].

Investment in community-based programming, local facilities (green spaces, baseball fields, basketball courts), and funding of school programming are potential strategies that can utilized to improve participation amongst youth in communities of need.

\section{Disparities in Care Received}

Beyond the ability to engage in sports due to financial restraints, many youth experience negative health outcomes in regard to management of their injuries. Even if access to sports exists for many youth, disparities in how their sport-related injuries are managed can prevent return to play. As mentioned above, insurance status plays a large role in determining access to sporting activity. As with other aspects of the health care system, difficulty in accessing care for sports injuries exists with public/no insurance [24]. For many schools, athletic trainers provide both acute/sub-acute medical care for students in need. The ability to treat injuries, guide care, and act as an advocate can provide front line care for sports injuries for many pediatric and adolescent athletes.

Post et al. examined athletic trainer access in Wisconsin and California schools and found that schools located in areas of lower socio-economic status had less access to athletic trainers $[25,26]$. This is reflective of a larger trend in which only $67 \%$ of schools have access to athletic trainers of which only $35 \%$ are full-time [27]. The presence of an athletic trainer has been particularly relevant in the ability to diagnose concussions, an entity in which a disparity exists for young athletes.

Kroshus et al examined concussion diagnoses and found that schools with an athletic trainer had a greater number of athletes diagnosed with a concussion as compared to schools without one [28]. Wallace et al also found similar disparities in 
regard to concussion knowledge and management based on race and presence of an athletic trainer [29••, 30]. The lack of an athletic trainer also has implications for bassline neurocognitive testing, particularly in public high schools with low-income populations.

Finally, intermittently intertwined with care disparities are the race/gender of the individuals who are providing care in schools. Barriers have been noted for female candidates in obtaining head athletic training positions [31]. Furthermore, the composition of the National Athletic Trainers Association has largely been white with very few trainers of color [32]. This is particularly important as although athletic trainers self-report a high level of cultural competence, they actually operate at a lower level of cultural competence with behaviors that do not mirror cultural awareness or sensitivity based on a study by Marra et al. [33] In at-risk communities (many of which have students of color), an urgent need exists to not only improve the presence of athletic trainers but also the cultural competency of those hired so that treatment for sports injuries can be improved. Barriers to receiving timely medical care can translate into barriers to participation due to time lost to injury.

\section{Pathology-Specific Disparities}

Integral to any discussion in regard to youth sports participation is the recognition of the disparities in care received for the actual injuries sustained due to participation. The lack of timely treatment for sports-related injuries in the pediatric and adolescent population can translate into delayed and/or cessation of participation tied to race and insurance status. This is particularly salient within pediatric sports medicine populations as guardians who have a lower level of education achieved, are non-English speaking, and have public insurance have lower health literary scores [34]. With the appropriate implementation of preventive programs, particularly in lower resourced communities, the physical and financial burden to the health care system through emergency room visits can be lessened for these sports injuries [35].

Bram et al. examined 915 pediatric patients who underwent ACL reconstruction and found that Black/Hispanic patients and those with public insurance had greater delays to surgery, more irreparable meniscus tears, and less physical therapy visits [36••]. This trend was also shown by Patel et al with publically insured patients having a greater incidence of treatment delays, meniscal injuries, and post-op stiffness [37]. Newman et al further showed that ACL reconstruction took twice as long for patients with public versus private insurance [38]. These delays in receiving care increase the risk of meniscal damage (leading to impaired sports performance) as well as prevent safe return to play due to decreased quantity of physical therapy sessions.
The potential long-term outcomes with delay in care have been clearly shown by Williams et al. In a group of 119 patients who underwent ACL reconstruction, the authors found that mean time to presentation was 56 days for the private insurance group and 136 days for the public insurance group [39・•]. Patients with public insurance also had more moderate to severe chondral injuries and meniscal tears that required debridement rather than repair. This trend has also been seen in patients with isolated meniscal pathology. Johnson et al. examined pediatric and adolescent patients and found that uninsured/publically insured patients experienced significant delays compared to commercially insured patients [40]. The timing to diagnosis via MRI is also impacted for these knee injuries. Beck et al examined 168 patients who underwent knee MRI and found that the time between injury and MRI was significantly longer for government-insured patients (34 days versus 67 days) as was the time between 1st visit and MRI and MRI order and completion [41].

Shoulder instability also falls within this trend. Hung et al. examined a series of pediatric and adolescent patients with shoulder instability and found that patients with public insurance had to wait 5 times longer for initial evaluation, 4 times longer for MRIs, were twice as likely to have bony pathology, and had post-operative dislocation at higher rates (24.3\%) [42].

Finally, concussion care is not spared from disparities in participation, particularly as delayed care can lead to prolonged duration out of participation. Lyons et al. retrospectively examined 11 years of the National Electronic Injury Surveillance System and found that Black children were less likely to be seen in the emergency department for sports-related head injuries as well to be diagnosed with concussions [43]. Furthermore, Wallace et al. examined concussion knowledge and found that white high school athletes had increased concussion knowledge as compared to African-American athletes, although this bridge was shown to lessen when African-American students had access to an athletic trainer [29]. As mentioned above, disparity in relation to treatment of injuries has many layers and can impact return to sport in many ways. Even when diagnosed with a concussion, post-concussion academic support demonstrated disparities with commercial insured, English speaking patient receiving more support, even when follow-up visits were attended [44].

Barriers to participation are complex and multi-factorial. As many youth sports athletes will suffer injuries due to sports specialization, ability to return to play in a timely fashion must be considered. Systemic disparities present within our health care system for certain pediatric and adolescent athletes make it difficult for injured athletes to return to participation and reap the benefits of health sports participation. 


\section{Conclusions}

As youth sports participation continues to increase, particularly with skill-based club sports, multiple barriers to participation exist for pediatric and adolescent athletes based on race, socio-economic status, and insurance. This starts at the high financial bar which exists to access club sports and then continues at every level of the health care system. The lack of access to athletic trainers as well as delays in care received for common sports pathologies such as ACL tears and concussions further prevents return to sporting activity after injury, representing a medical barrier to sports participation. A comprehensive program which engages parents, athletes, coaches, community leaders, school administrators, and the health care system will be critical for overcoming these barriers.

\section{Declarations}

Human and Animal Rights and Informed Consent This article does not contain any studies with human or animal subjects performed by any of the authors.

Conflict of Interest Nirav Pandya is a consultant with Orthopediatrics.

Open Access This article is licensed under a Creative Commons Attribution 4.0 International License, which permits use, sharing, adaptation, distribution and reproduction in any medium or format, as long as you give appropriate credit to the original author(s) and the source, provide a link to the Creative Commons licence, and indicate if changes were made. The images or other third party material in this article are included in the article's Creative Commons licence, unless indicated otherwise in a credit line to the material. If material is not included in the article's Creative Commons licence and your intended use is not permitted by statutory regulation or exceeds the permitted use, you will need to obtain permission directly from the copyright holder. To view a copy of this licence, visit http://creativecommons.org/licenses/by/4.0/.

\section{References}

Papers of particular interest, published recently, have been highlighted as:

- Of importance

-• Of major importance

1. Ng K, Cooper J, McHale F, Clifford J, Woods C. Barriers and facilitators to changes in adolescent physical activity during COVID-19. BMJ Open Sport Exerc Med. 2020;6(1):e000919. https://doi.org/10.1136/bmjsem-2020-000919.

2. McGuine TA, Biese KM, Petrovska L, Hetzel SJ, Reardon C, Kliethermes S, Bell DR, Brooks A, Watson AM. Mental health, physical activity, and quality of life of US adolescent athletes during COVID-19-related school closures and sport cancellations: a study of 13000 athletes. J Athl Train. 2020. https://doi.org/10. 4085/1062-6050-0478.20 A total of 13,002 adolescent athletes filled out a survey in regards to mental health, physical activity, and quality of life during COVID19 with females having elevated levels of anxiety, team sport athletes having elevated levels of depression, and athletes from high poverty level areas having lower quality of life scores.

3. Lee SM, Burgeson CR, Fulton JE, Spain CG. Physical education and physical activity: results from the School Health Policies and Programs Study 2006. J Sch Health. 2007;77:435-63.

4.• The Aspen Institute. State of Play 2019. Accessed online February $8^{\text {th }}, 2020$ at https://www.aspeninstitute.org/wp-content/uploads/ 2019/10/2019_SOP_National_Final.pdf. In this comprehensive report, data is presented to demonstrate that children from low income households face increasing participation barriers and on average families spends $\$ 6893$ per child for one sport each year.

5. Jayanthi NA, Pinkham C, Durazo-Arivu R, Dugas L, Luke A. The risks of sports specialization and rapid growth in young athletes. Clin J Sports Med. 2011;21:157.

6.• Bell DR, Post EG, Biese K, Bay C, Valovich MLT. Sport specialization and risk of overuse injuries: a systematic review with metaanalysis. Pediatrics. 2018;142:e20180657. https://doi.org/10.1542/ peds.2018-0657 This meta-analysis of 4 studies found that sport specialization is associated with over-use musculoskeletal injuries.

7. DiCesare CA, Montalvo A, Foss KDB, Thomas SM, Hewett TE, Jayanthi NA, Myer GD. Sport specialization and coordination differences in multisport adolescent female basketball, soccer, and volleyball athletes. J Athl Train. 2019;54:1105-14. https://doi.org/ 10.4085/1062-6050-407-18.

8. Olsen SJ 2nd, Fleisig GS, Dun S, Loftice J, Andrews JR. Risk factors for shoulder and elbow injuries in adolescent baseball pitchers. Am J Sports Med. 2006;34:905-12.

9. NCAA. Estimated probability of competing in college athletics. Accessed online February $8^{\text {th }}, 2021$ at https://www.ncaa.org/ about/resources/research/estimated-probability-competing-collegeathletics

10. NCAA. Estimated probability of competing professionally. Accessed online February $8^{\text {th }}, 2021$ at https://www.ncaa.org/ about/resources/research/estimated-probability-competingprofessional-athletics

11. Rugg C, Kadoor A, Feeley BT, Pandya NK. The effects of playing multiple high school sports on National Basketball Association Players' Propensity for Injury and Athletic Performance. Am J Sports Med. 2018;46:402-8. https://doi.org/10.1177/ 0363546517738736.

12. Steinl GK, Padaki AS, Irvine JN, Popkin CA, Ahmad CS, Lynch TS. The prevalence of high school multi-sport participation in elite national football league athletes. Phys Sportsmed. 2020;6:1-4. https://doi.org/10.1080/00913847.2020.1856632.

13. Wilhelm A, Choi C, Deitch J. Early sport specialization: effectiveness and risk of injury in professional baseball players. Orthop J Sports Med. 2017;5(9):2325967117728922. https://doi.org/10. $1177 / 2325967117728922$.

14. Buckley PS, Ciccotti MC, Bishop M, Kane P, Selverian S, Exume D, D'Angelo J, Emper W, Freedman KB, Hammoud S, Cohen SB, Ciccotti MG. Youth single-sport specialization in professional baseball players. Orthop J Sports Med. 2020;8: 2325967120907875. https://doi.org/10.1177/2325967120907875.

15. Farrey T, Walters S. The gentrification of college hoops. Accessed online February $8^{\text {th }}, 2021$ at https://theundefeated.com/features/ gentrification-of-ncaa-division-1-college-basketball/

16. Gregory S. How kids' sports became a $\$ 15$ billion industry. Accessed online February $8^{\text {th }}, 2021$ at http://time.com/magazine/ us/4913681/september-4th-2017-vol-190-no-9-u-s/

17. TD Ameritrade. Investor survey: parent perspectives on the cost of competitive youth sports. Accessed online February $8^{\text {th }}, 2021$ at https://s1.q4cdn.com/959385532/files/doc_downloads/research/ Sports-Parents-Survey-Report_2016.pdf. 
18. Bridging the Gap. Sports participation in secondary schools: resources available and inequalities in participation: a BTG research brief. Accessed July 2019 at http://www.bridgingthegapresearch. org.

19.• Jayanthi NA, Holt DB Jr, LaBella CR, Dugas LR. Socioeconomic factors for sports specialization and injury in youth athletes. Sports Health. 2018;10:303-10. https://doi.org/10.1177/ 1941738118778510 In a survey of greater than 1000 athletes, athletes of higher socio-economic status reported more serious over-use injuries due to higher sports specialization rates, more hours per week playing organized sports, and greater participation in individual sports.

20.• Post EG, Green NE, Schaefer DA, Trigsted SM, Brooks MA, McGuine TA, Watson AM, Bell DR. Socioeconomic status of parents with children participating on youth club sport teams. Phys Ther Sport. 2018;32:126-32. https://doi.org/10.1016/j.ptsp.2018. 05.014949 athletes at club sports events completed a survey which demonstrated that families spend a median of $\mathbf{1 5 0 0}$ dollars per year on club sports with household incomes greaer than $\$ 100,000$ (with bachelor's level or higher of education) more likely to be participating.

21. Hyde ET, Omura JD, Fulton JE, Lee SM, Piercy KL, Carlson SA. Disparities in youth sports participation in the U.S., 2017-2018. Am J Prev Med. 2020;59:e207-10. https://doi.org/10.1016/j.amepre. 2020.05.011 In a review of the National Survey of Children's Health, sports participation was highest in male, white, nonHispanic households with higher levels of education and income.

22. Fabricant PD, McLaren SH, Suryavanshi JR, Nwachukwu BU, Dodwell ER. Association between government health insurance status and physical activity in American youth. J Pediatr Orthop. 2019;39:e552-7. https://doi.org/10.1097/BPO. 0000000000001329 .

23. Kroshus E, Sonnen AJ, Chrisman SP, Rivara FP. Association between community socioeconomic characteristics and access to youth flag football. Inj Prev. 2019;25(4):278-82. https://doi.org/ 10.1136/injuryprev-2017-042677.

24. Wiznia DH, Nwachuku E, Roth A, Kim CY, Save A, Anandasivam NS, Medvecky M, Pelker R. The influence of medical insurance on patient access to orthopaedic surgery sports medicine appointments under the Affordable Care Act. Orthop J Sports Med. 2017;5(7): 2325967117714140. https://doi.org/10.1177/2325967117714140.

25.• Post E, Winterstein AP, Hetzel SJ, Lutes B, McGuine TA. School and community socioeconomic status and access to athletic trainer services in Wisconsin secondary schools. J Athl Train 2019;54: 177-181. https://doi.org/10.4085/1062-6050-440-17. In a survey of schools in Wisconsin, schools located in communities with lower household incomes had more limited access to athletic trainers.

26. Post EG, Roos KG, Rivas S, Kasamatsu TM, Bennett J. Access to athletic trainer services in California secondary schools. J Athl Train. 2019;54:1229-36. https://doi.org/10.4085/1062-6050-26819.

27. Huggins RA, Coleman KA, Attanasio SM, Cooper GL, Endres BD, Harper RC, Huemme KL, Morris RF, Pike Lacy AM, Peterson BC, Pryor RR, Casa DJ. Athletic trainer services in the secondary school setting: the athletic training locations and services project. J Athl Train. 2019;54:1129-39.

28. Kroshus E, Rivara FP, Whitlock KB, Herring SA, Chrisman SPD. Disparities in athletic trainer staffing in secondary school sport: implications for concussion identification. Clin J Sport Med. 2017;27:542-7. https://doi.org/10.1097/JSM.0000000000000409.

29.• Wallace J, Covassin T, Moran R. Racial disparities in concussion knowledge and symptom recognition in American adolescent athletes. J Racial Ethn Health Disparities. 2018;5:221-8. https://doi. org/10.1007/s40615-017-0361-1 In a survey of 577 athletes, white adolescent athletes had more concussion knowledge than African-American athletes. This disparity decreased when African-American athletes were given access to an athletic trainer, Racial Disparities in Concussion Knowledge and Symptom Recognition in American Adolescent Athletes.

30. Campbell J, Howland J, Hess C, Nelson K, Stern RA, Torres A, Olshaker J. Disparities in baseline neurocognitive testing for student concussion management in Massachusetts high schools. BMJ Open Sport Exerc Med. 2020;6:e000752. https://doi.org/10.1136/ bmjsem-2020-000752.

31. Mazerolle SM, Eason CM. Barriers to the role of the head athletic trainer for women in National Collegiate Athletic Association Division II and III settings. J Athl Train. 2016;51:557-65. https:// doi.org/10.4085/1062-6050-51.9.08 Epub 2016 Aug 22.

32. National Athletic Trainers Association. Ethnicity demographic data. Accessed online February $8^{\text {th }}, 2021$ at https://www.nata.org/ sites/default/files/ethnicity-demographics.pdf

33. Marra J, Covassin T, Shingles RR, Canady RB, Mackowiak T. Assessment of certified athletic trainers' levels of cultural competence in the delivery of health care. J Athl Train. 2010;45:380-5. https://doi.org/10.4085/1062-6050-45.4.380.

34. Su L, Shaw K, Serpa RO, Grotts J, Bowen R, Beck J. Evaluation of general and musculoskeletal health literacy disparities in pediatric sports injury patient and guardian populations. J Pediatr Orthop. 2020;40:e237-42. https://doi.org/10.1097/B PO. 0000000000001414.

35. Ryan JL, Pracht EE, Orban BL. Inpatient and emergency department costs from sports injuries among youth aged 5-18 years. BMJ Open Sport Exerc Med. 2019;5:e000491. https://doi.org/10.1136/ bmjsem-2018-000491.

36.• Bram JT, Talathi NS, Patel NM, DeFrancesco CJ, Striano BM, Ganley TJ. How do race and insurance status affect the care of pediatric anterior cruciate ligament injuries? Clin J Sport Med. 2020;30:e201-6 In this review of 915 pediatric ACL patients Black/Hispanic children and those with public insurance have greater surgery delays, more irreparable meniscus tears, less PT visits, and greater residual weakness at 9 months after surgery.

37. Patel AR, Sarkisova N, Smith R, Gupta K, VandenBerg CD. Socioeconomic status impacts outcomes following pediatric anterior cruciate ligament reconstruction. Medicine (Baltimore). 2019;98 (17):e15361. https://doi.org/10.1097/MD.0000000000015361.

38. Newman JT, Carry PM, Terhune EB, Spruiell M, Heare A, Mayo M, Vidal AF. Delay to reconstruction of the adolescent anterior cruciate ligament: the socioeconomic impact on treatment. Orthop J Sports Med. 2014;2(8):2325967114548176. https://doi.org/10. $1177 / 2325967114548176$.

39.• Williams AA, Mancini NS, Solomito MJ, Nissen CW, Milewski MD. Chondral injuries and irreparable meniscal tears among adolescents with anterior cruciate ligament or meniscal tears are more common in patients with public insurance. Am J Sports Med. 2017;45:2111-5. https://doi.org/10.1177/0363546517707196 In a review of 119 patients, the authors found delayed presentation in the public insurance group which led to an increased incidence of moderate to severe chondral injuries, and meniscus tears that could not be repaired.

40. Johnson TR, Nguyen A, Shah K, Hogue GD. Impact of insurance status on time to evaluation and treatment of meniscal tears in children, adolescents, and college-aged patients in the United States. Orthop J Sports Med. 2019;7(10):2325967119875079. https://doi. org/10.1177/2325967119875079.

41. Beck JJ, West N, Shaw KG, Jackson N, Bowen RE. Delays in obtaining knee MRI in pediatric sports medicine: impact of insurance type. J Pediatr Orthop. 2020;40:e952-7. https://doi.org/10. 1097/BPO.0000000000001653. 
42. Hung NJ, Darevsky DM, Pandya NK. Pediatric and adolescent shoulder instability: does insurance status predict delays in care, outcomes, and complication rate? Orthop J Sports Med. 2020;8: 2325967120959330.

43. Lyons TW, Miller KA, Miller AF, Mannix R. Racial and ethnic differences in emergency department utilization and diagnosis for sports-related head injuries. Front Neurol. 2019;10:690. https://doi. org/10.3389/fneur.2019.00690.
44. Snedden TR, Pierpoint LA, Currie DW, Comstock RD, Grubenhoff JA. Postconcussion academic support in children who attend a primary care provider follow-up visit after presenting to the emergency department. J Pediatr. 2019;209:168-75. https://doi.org/10. 1016/j.jpeds.2019.01.041.

Publisher's note Springer Nature remains neutral with regard to jurisdictional claims in published maps and institutional affiliations. 